\title{
Pre-Operative Perihepatic Lymph Node Assessment in Colorectal Cancer Liver Metastasis-A Review of Current Literature
}

\author{
Tuck Leong Yong1* ${ }^{*}$ David Burrows ${ }^{2}$, Chris Christophi ${ }^{3}$ \\ ${ }^{1}$ Department of Surgery, Northern Health, Epping, Australia \\ ${ }^{2}$ Department of Radiology, Northern Health, Epping, Australia \\ ${ }^{3}$ Department of Surgery, Austin Health, Heidelberg, Australia \\ Email: *soiyan@hotmail.com
}

How to cite this paper: Yong, T.L., Burrows, D. and Christophi, C. (2017) Pre-Operative Perihepatic Lymph Node Assessment in Colorectal Cancer Liver Metastasis-A Review of Current Literature. Open Journal ot Medical Imaging, 7, 89-99.

https://doi.org/10.4236/ojmi.2017.73009

Received: August 20, 2017

Accepted: September 10, 2017

Published: September 13, 2017

Copyright $\odot 2017$ by authors and Scientific Research Publishing Inc. This work is licensed under the Creative Commons Attribution International License (CC BY 4.0).

http://creativecommons.org/licenses/by/4.0/

\section{(c) (i) Open Access}

\begin{abstract}
Objective: Perihepatic lymph node involvement in colorectal cancer liver metastases is a negative prognostic factor. Resection of certain nodal stations around the liver has been shown to possibly improve survival. The aim of this review is to interrogate current literature on pre-operative investigations in diagnosing lymph node involvement. Method: A systematic review was conducted of articles published since 2006 to determine usefulness of pre-operative imaging in diagnosing lymph node involvement in colorectal cancer liver metastases. Results: Only 2 papers met the inclusion criteria for this study. Computed tomography (CT) scans were found to have sensitivities of $33 \%$ and $40 \%$, specificities of $94 \%$ and $92 \%$, positive predictive values (PPV) of $56 \%$ and $30 \%$, and negative predictive values (NPV) of $85 \%$ and $95 \%$. Positron emission tomography (PET) was studied in one of the paper and was found to have sensitivity, specificity, PPV and NPV of $57 \%, 100 \%, 100 \%$, and $88 \%$ respectively. Conclusion: There is a significant lack of research on pre-operative investigations of perihepatic lymph node involvement in colorectal cancer liver metastases. Pre-operative CT and PET scans in assessing perihepatic lymph nodes were shown to be inaccurate. Newer pre-operative imaging modalities and research would be needed.
\end{abstract}

\section{Keywords}

Cancer Staging, Colorectal Carcinoma, Hepatic Metastasis, CT Scan, Lymph Nodes, Positron-Emission Tomography

\section{Introduction}

Colorectal cancer is a dominant disease in the Australian society. In 2012, 14,958 
new cases of bowel cancers were diagnosed in Australia, making it the $3^{\text {rd }}$ most common cancer diagnosis [1]. About $50 \%$ of patients with colorectal carcinoma will eventually develop metastases, with liver and lungs being the most common sites [2] [3] [4] [5] [6]. For patients with liver metastases, surgery remains the gold standard of treatment with 5-year survival rates approaching 50\% [6]-[11].

Studies have shown that perihepatic lymph node involvement from colorectal cancer liver metastases is a negative prognostic factor. Survival is very poor with 5 -year survival rates ranging from $1 \%-5 \%$ [12] [13] [14] [15] [16]. There is some survival benefit in surgical resection of certain nodal stations around the hepatic hilar region [17] [18] [19] [20] [21]. Therefore, accurate staging is paramount for decision making pre-operatively.

Most commonly, staging of patients with colorectal cancer involves abdominal ultrasound and computed tomography (CT) scan as well as chest X-ray or CT chest. Positron emission tomography (PET) scan is used more frequently these days as a staging tool. Currently, despite multiple modalities being available, there is no diagnostic guideline in aiding a radiologist to differentiate a metastatic lymph node from a non-metastatic one [22] [23] [24] [25].

Therefore, this review aims to assess the current literature on pre-operative investigations and to determine each modality's usefulness in diagnosing lymph node involvement. In view of its prognostic value, lymph node pre-operative staging needs to be considered important as it potentially changes decision-making process in colorectal cancer disease management.

\section{Methods}

A literature search was performed in May 2016 using PubMed and EMBASE databases. Search terms used included "liver or hepatic secondaries, liver or hepatic metastasis, computer tomography, magnetic resonance, ultrasound, positron emission tomography, and perihepatic or hepatic pedicle or perihilar lymph node". Search was filtered for articles in English, on human subjects and published since 1 January 2006. Articles were assessed based on information gleaned from the titles and abstracts initially. If deemed appropriate for the purpose of this study, complete articles were obtained for further assessment. References from these selected papers were also perused to identify any article which could be included in this study.

The main inclusion criteria were assessment of pre-operative investigations to ascertain perihepatic lymph node status. Studies included must have clearly stated definition to determine lymph node involvement pre-operatively. Review articles, abstracts and case reports were excluded. Selected studies were graded using QUADAS tool [26]. Accuracy of each imaging modality from each study was recorded for further analysis.

\section{Results}

Based on the search terms mentioned before, 38 papers were initially identified 
from the databases. Thirty-three papers were selected for further scrutiny of their titles and abstracts. Upon further scrutiny, only 2 studies met the inclusion criteria of this study. Figure 1 illustrated the flow of paper selection based on PRISMA guidelines. No additional paper was identified from the references of reviewed papers.

The 2 articles included in the final analysis were by Grobmyer et al. and Rau et al. Characteristics of each paper were shown in Table 1 [27]. Based on QUADAS
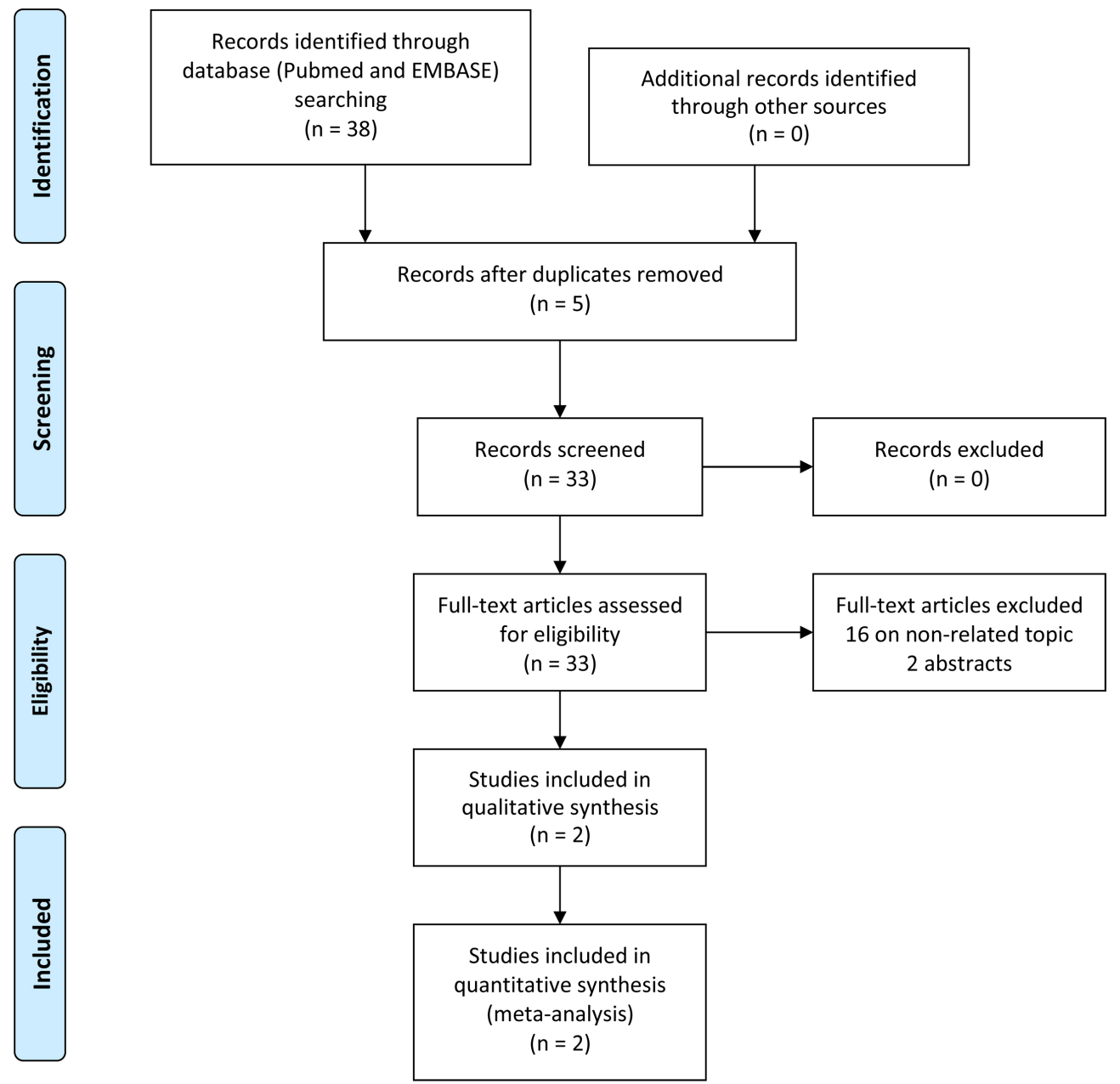

Figure 1. PRISMA flow diagram.

Table 1. Study characteristics.

\begin{tabular}{|c|c|c|c|c|c|c|}
\hline Reference & Year & Type of study & Comparison & $\begin{array}{l}\text { Level of } \\
\text { evidence }\end{array}$ & $\begin{array}{l}\text { Cases (no. of } \\
\text { lymph nodes } \\
\text { assessed) }\end{array}$ & Time \\
\hline Rau et al. [28] & 2012 & $\begin{array}{l}\text { Prospective } \\
\text { comparison }\end{array}$ & $\begin{array}{l}\text { Pre-operative } \mathrm{CT} \text { vs } \\
\text { Intraoperative findings }\end{array}$ & III-1 & $76(241)$ & $\begin{array}{c}\text { January } \\
\text { 2008-June } 2006\end{array}$ \\
\hline $\begin{array}{c}\text { Grobmyer et } \\
\text { al. [29] }\end{array}$ & 2006 & $\begin{array}{l}\text { Retrospective } \\
\text { comparison }\end{array}$ & $\begin{array}{l}\text { Pre-operative CT } \\
\text { vs PET vs } \\
\text { intraoperative } \\
\text { findings }\end{array}$ & III-2 & $100(316)$ & $\begin{array}{c}\text { July 2002-June } \\
2004\end{array}$ \\
\hline
\end{tabular}


tool scoring system, the paper by Grobmyer et al. attained a score of 9 while the one by Rau et al. had a score of 10 . Both papers were of equal quality.

\subsection{Study Population}

The study by Rau et al., included all consecutive patients who underwent surgical treatment of resectable colorectal liver metastases at Hopital Beaujon, France between January 2008 and June 2010 [28]. A total of 78 consecutive patients were included. Two were eventually excluded as no curative surgery was performed due to peritoneal carcinomatosis. From these 76 patients, hepatic pedicle lymph node dissection yielded 241 lymph nodes. Thirty (12.5\%) lymph nodes were found to have metastatic cells after pathological analysis.

In the article by Grobmyer et al., $75 \%$ of 100 patients included had metastatic colorectal cancer [29]. Twenty-five patients had other types of hepatic malignancies. Nevertheless, all patients underwent lymph node sampling with a total of 316 lymph nodes harvested. Twenty-two (7\%) lymph nodes from 15 patients had metastatic disease.

Therefore, for this review, a total of 178 patients underwent liver resections and hepatic pedicle lymphadenectomy, yielding 557 lymph nodes. Of these 52 lymph nodes (9.3\%) had metastatic disease.

\subsection{Definition of Lymph Node Involvement}

In the study by Rau et al., CT diagnoses of metastatic lymph nodes were compared against histologically proven metastatic nodes [28]. The authors defined metastatic nodes on CT as lymph nodes larger than $1 \mathrm{~cm}$ in the short axis diameter, round shaped, irregularly contoured and/or heterogeneous in appearance.

Size was also used by Grobmyer et al. [29]. However, they defined metastatic involvement on CT differently depending on position of the nodal station. Portocaval nodes were considered involved if cross product of dimensions was $\geq 0.65 \mathrm{~cm}^{2}$. Pancreaticoduodenal and hepatic artery nodes were considered involved as long as CT could detect them. As for PET scan detected nodes, these were considered positive if there was increased fluorodeoxyglucose (FDG) uptake in the perihepatic regions.

\subsection{Accuracy of Pre-Operative Scans}

In the paper by Rau et al., accuracy of CT scan was calculated on a per-patient basis [28]. On the other hand, Grobmyer et al., analyzed accuracy of CT scan in detecting metastatic lymph node based on a per-nodal station basis [29]. The heterogeneity of analysis made pooling of results impossible. However, for PET scan, they calculated its accuracy on a per-patient basis as a PET scan was not able to geographically localise exactly the location of an FDG-avid node.

CT scan showed suspicious lymph nodes in 20 lymph node stations in the paper by Grobmyer et al. [29]. Of these only 8 had metastatic cells confirmed on 
histopathology. Of all the 236 lymph node stations assessed, 216 were thought to be negative for metastasis. But there were 7 metastatic lymph node stations among them found on pathology. As a result, sensitivity, specificity, positive predictive value and negative predictive value of pre-operative CT were calculated to be $40 \%, 92 \%, 30 \%$ and $95 \%$ respectively. In comparison, in the paper by Rau et al., lymph node metastasis was suspected in 9 patients based on findings from pre-operative CT [28]. However, only 5 were confirmed to have nodal metastasis. Of the remaining 67 patients deemed to have no nodal disease on CT, 4 turned out to have disease. This gave sensitivity, specificity, positive predictive value (PPV) and negative predictive value (NPV) for CT on a per-patient basis of $33 \%, 94 \%, 56 \%$ and $85 \%$ respectively.

PET scan was only studied in the paper by Grobmyer et al. [29]. Results were analysed on a per-patient basis on 66 patients. No explanation was given as to the omission of the other 34 patients from having a pre-operative PET scan. Four patients were suspected to have nodal metastasis based on pre-operative PET scans. PET scans failed to detect nodal metastasis in 7 patients. The overall sensitivity, specificity, PPV and NPV for PET scan were 57\%, 100\%, 100\% and $88 \%$ respectively (Table 2 ).

\section{Discussion}

Perihepatic lymph node is quite frequently identified on pre-operative imaging. However, there is a significant challenge in differentiating a metastatic lymph node from one that is not [30] [31] [32]. In colorectal cancer hepatic metastases, presence of perihilar lymphadenopathy from nodal metastases would portend a poor prognosis with recent studies indicating a 5-year survival rate of $1 \%-5 \%$ [12] [13]. Pre-operative staging investigations thus have an important role in selecting appropriate patients for curative treatments.

Unfortunately, thus far, there has not been any official recommendation to guide the diagnosis of lymph node metastasis. CT has been most commonly used to stage colorectal cancer metastasis pre-operatively. Size and shape has been frequently used as means to help differentiate benign from malignant lymph nodes [33] [34]. To be deemed positive, a malignant lymph node should be larger than $1 \mathrm{~cm}$ on its short axis diameter, asymmetrical and/or present in clusters [30] [33]. Sensitivity and specificity of CT scan in lymph node staging were estimated to be $52 \%-55 \%$ and $74 \%-78 \%$ respectively [35] [36]. In another

Table 2. Summary of results.

\begin{tabular}{cccccc}
\hline Reference & Imaging & $\begin{array}{c}\text { Sensitivity } \\
(\%)\end{array}$ & $\begin{array}{c}\text { Specificity } \\
(\%)\end{array}$ & PPV (\%) & NPV (\%) \\
\hline Rau et al. [28] & $\mathrm{CT}^{\dagger}$ & 33 & 93 & 56 & 85 \\
Grobmyer et & $\mathrm{CT}^{\ddagger}$ & 40 & 92 & 30 & 95 \\
al. [29] & $\mathrm{PET}^{\dagger}$ & 57 & 100 & 100 & 88 \\
\hline
\end{tabular}

${ }^{\dagger}$ Calculations were based on a per-patient analysis. ${ }^{*}$ Calculations were based on a per-nodal station analysis. 
meta-analysis CT nodal staging sensitivity and specificity were $70 \%$ and $78 \%$ respectively [37].

This seemed higher than the sensitivity quoted in this review. Sensitivity of CT scans for perihepatic metastatic lymph nodes were low between $33 \%-40 \%$. Specificity of CT scans was higher, however, with reported values of more than $90 \%$. The differences in sensitivity and specificity values here compared to the studies by Bipat et al. and Dighe et al. could be attributed to the location of the nodes [36] [37]. Here, Rau et al. and Grobmyer et al., studied CT detection of nodes around the liver, whereas Bipat et al. and Dighe et al. looked at nodes around the intestinal mesentery or perirectal regions [28] [29] [36] [37].

A significant problem of CT scan using size criteria to define nodal metastasis is that cancer can be present in nodes less than $1 \mathrm{~cm}$ in size [30]. In a paper estimating frequency of perirectal nodal metastasis, the majority of metastasis occurred in lymph nodes smaller than $1 \mathrm{~cm}$ [22] [38].

To improve the detection of extrahepatic metastasis, FDG-PET had been investigated quite thoroughly in the literature. In a study, which located 40 intra-abdominal lymph node recurrences from colorectal cancer, FDG-PET combined with CT was found to have sensitivity of $100 \%$, specificity of $40 \%$, PPV of $93 \%$, and NPV of $100 \%$ [39]. In another paper however, PET was noted to have low sensitivity but high specificity (28.6\% and $92.9 \%$ respectively) [40]. In comparison, PET scan was also found to be low in sensitivity but high in specificity as seen in Grobmyer et al. in this review [29]. PET scan was thought to be useful for its ability to detect malignant lymph node without depending on size of the node [41]. However, a guideline from Canada was published recently which did not recommend the routine use of PET scan for staging of colorectal cancer [42].

MRI scan was not scrutinized in this review. There has been no specific study on the use of MRI in locating malignancy within perihepatic lymph nodes. MRI is known to have a high soft tissue contrast and should improve detection of disease when size criterion was combined with border and signal morphology of the node [22]. High resolution MRI has the ability to visualize a lymph node as small as $2 \mathrm{~mm}$ in diameter [30]. In a study of 437 lymph nodes from patients with rectal carcinoma, MRI detection of diseased lymph nodes had sensitivity of $85 \%$ and specificity of $97 \%$ [43]. Recent developments in MRI have seen the use of ultra-small superparamagnetic particles of iron oxide (USPIO) as a contrast specific for nodal tissues. An increase in signal intensity is noted in a diseased node. This was shown to have high sensitivity and specificity (93\% and $96 \%$ respectively) for malignant lymph nodes in rectal cancer [44]. MRI utilizing diffusion-weighted imaging (DWI) has also emerged as a possible tool for discriminating between malignant and non-malignant lymph nodes. Cho et al. reported a sensitivity of $78 \%$ and specificity of $67 \%$ using this in staging of colorectal cancer [45].

This current review has shown a significant weakness in pre-operative imaging for colorectal cancer liver metastases prior to resectional surgery. CT and 
PET have both been shown to lack sensitivity although specificity is quite high. The main limitation of this review nevertheless is the small number of papers included for analysis. The definition used in each paper to define an involved perihilar lymph node was also different, disallowing any useful attempt at pooled data analysis. Newer studies would hopefully compare other modalities in future articles. The prognostic value of perihepatic lymph node cannot be underestimated and would be a useful knowledge pre-operatively in selection of appropriate patient treatment. With modern chemotherapy including anti-lymphangiogenic therapies, and better surgical techniques, survival rates could be improved in these patients [7] [46] [47].

Current technology of imaging is not yet good enough to accurately stage perihepatic lymph nodes. Regional lymphadenectomy during liver resection appears to be the most definitive tool in staging of nodal status in colorectal cancer hepatic metastases with minimal additional morbidity and mortality [48] [49] [50]. However, value of its benefit to patient survival remained controversial but promising data is beginning to appear [7] [17]. This is especially for nodes around the hepaticoduodenal ligament and the retropancreatic regions [7] [17].

\section{Conclusion}

There is a significant lack of research on investigations of perihepatic lymph node involvement in colorectal cancer liver metastases. This is a major oversight in the current literature in view of the significance of lymph node status in patient prognosis. This review has highlighted the inaccuracy in pre-operative CT and PET scans in assessing perihepatic lymph nodes. Newer pre-operative imaging modalities and research would be needed.

\section{Disclosure}

The authors declare that there is no conflict of interest, financial or otherwise, regarding the publication of this paper.

\section{References}

[1] Cancer Australia. Bowel Cancer Statistics. Available from: https://bowel-cancer.canceraustralia.gov.au/statistics (Last Accessed 6 May 2016)

[2] McNally, S.J. and Parks, R.W. (2013) Surgery for Colorectal Liver Metastases. Digestive Surgery, 30, 337-347. https://doi.org/10.1159/000351442

[3] Kanas, G.P., Taylor, A., Primrose, J.N., Langeberg, W.J., Kelsh, M.A., Mowat, F.S., et al. (2012) Survival after Liver Resection in Metastatic Colorectal Cancer: Review and Meta-Analysis of Prognostic Factors. Clinical Epidemiology, 4, 283-301.

[4] Misiakos, E.P., Karidis, N.P. and Kouraklis, G. (2011) Current Treatment for Colorectal Liver Metastases. World Journal of Gastroenterology, 17, 4067-4075. https://doi.org/10.3748/wjg.v17.i36.4067

[5] Sorbye, H. (2014) Recurrence Patterns after Resection of Liver Metastases from Colorectal Cancer. In: Otto, F., Lutz, M.P., Eds., Early Gastrointestinal Cancers II: Rectal Cancer. Springer International Publishing, Switzerland, 243-252. 
[6] Kulaylat, A.N., Schubart, J.R., Stokes, A.L., Bhayani, N.H., Wong, J., Kimchi, E.T., et al. (2014) Overall Survival by Pattern of Recurrence Following Curative Intent Surgery for Colorectal Liver Metastasis. Journal of Surgical Oncology, 110, 1011-1015. https://doi.org/10.1002/jso.23756

[7] Pulitano, C., Bodingbauer, M., Aldrighetti, L., Choti, M.A., Castillo, F., Schulick, R.D., et al. (2012) Colorectal Liver Metastasis in the Setting of Lymph Node Metastasis: Defining the Benefit of Surgical Resection. Annals of Surgical Oncology, 19, 435-442. https://doi.org/10.1245/s10434-011-1902-1

[8] De Jong, M.C., Pulitano, C., Ribero, D., Strub, J., Mentha, G., Schulick, R.D., et al. (2009) Rates and Patterns of Recurrence Following Curative Intent Surgery for Colorectal Liver Metastasis. Annals of Surgery, 250, 440-448.

[9] Oh, S.Y., Kim, D.Y. and Suh, K.W. (2015) Oncologic Outcomes Following Metastasectomy in Colorectal Cancer Patients Developing Distant Metastases after Initial Treatment. Annals of Surgical Treatment Research, 88, 253-259. https://doi.org/10.4174/astr.2015.88.5.253

[10] Augestad, K.M., Bakaki, P.M., Rose, J., Crawshaw, B.P., Lindsetmo, R.O., Dorum, L.M., et al. (2015) Metastastic Spread Pattern after Curative Colorectal Cancer Surgery. A Retrospective, Longitudinal Analysis. Cancer Epidemiology, 39, 734-744. https://doi.org/10.1016/j.canep.2015.07.009

[11] Butte, J.M., Gonen, M., Allen, P.J., Kingham, P., Sofocleous, C.T., DeMatteo, R.P., et al. (2015) Recurrence after Partial Hepatectomy for Metastatic Colorectal Cancer: The Potentially Curative Role of Salvage Re-Resection. Annals of Surgical Oncology, 22, 2761-2771. https://doi.org/10.1245/s10434-015-4370-1

[12] Rodgers, M.S. and McCall, J.L. (2000) Surgery for Colorectal Liver Metastases with Hepatic Lymph Node Involvement: A Systemic Review. British Journal of Surgery, 87, 1142-1155. https://doi.org/10.1046/j.1365-2168.2000.01580.x

[13] Gurusamy, K.S., Imber, C. and Davidson, B.R. (2008) Management of the Hepatic Lymph Nodes during Resection of Liver Metastases from Colorectal Cancer: A Systematic Review. HPB Surgery, 2008, Article ID: 684150. https://doi.org/10.1155/2008/684150

[14] Elias, D., Saric, J., Jaeck, D., Arnaud, J.P., Gayet, B., Rivoire, M., et al. (1996) Prospective Study of Microscopic Lymph Node Involvement of the Hepatic Pedicle during Curative Hepatectomy for Colorectal Metastases. British Journal of Surgery, 83, 942-945. https://doi.org/10.1002/bjs.1800830717

[15] Beckurts, K.T.E., Holscher, A.H., Thorban, S., Bollschweiler, E. and Siewert, J.R. (1997) Significance of Lymph Node Involvement at the Hepatic Hilum in the Resection of Colorectal Liver Metastases. British Journal of Surgery, 84, 1081-1084. https://doi.org/10.1002/bjs.1800840811

[16] Viana, E.F., Herman, P., Siqueira, S.C., Taka, T., Carvalho, P., Coelho, F.F., et al. (2009) Lymphadenectomy in Colorectal Cancer Liver Metastases Resection: Incidence of Hilar Lymph Nodes Micrometastasis. Journal of Surgical Oncology, 100, 534-537. https://doi.org/10.1002/jso.21357

[17] Jaeck, D., Nakano, H., Bachellier, P., Inoue, K., Weber, J.C., Oussoultzoglou, E., et al. (2002) Significance of Hepatic Pedicle Lymph Node Involvement in Patients with Colorectal Liver Metastases: A Prospective Study. Annals of Surgical Oncology, 9 , 430-438. https://doi.org/10.1007/BF02557264

[18] Jaeck, D. (2003) The Significance of Hepatic Pedicle Lymph Nodes Metastases in Surgical Management of Colorectal Liver Metastases and of Other Liver Malignancies. Annals of Surgical Oncology, 10, 1007-1011. 
https://doi.org/10.1245/ASO.2003.09.903

[19] Jaeck, D., Oussoultzoglou, E. and Rosso, E. (2007) Hepatectomy for Colorectal Metastases in the Presence of Extrahepatic Disease. Surgical Oncology Clinics of North America, 16, 507-523.

[20] Christophi, C., Nguyen, L., Muralidharan, V., Nikfarjam, M. and Banting, J. (2014) Lymphatics and Colorectal Liver Metastases: The Case for Sentinel Node Mapping. $H P B, 16,124-130$. https://doi.org/10.1111/hpb.12118

[21] Wakai, T., Shirai, Y., Sakata, J., Nagahashi, M., Kaneko, K. and Hatakeyama, K. (2009) Hepatic Lymph Node Dissection Provides a Survival Benefit for Patients with Nodal Disease of Colorectal Carcinoma Liver Metastases. Hepato-Gastroenterology, 56, 186-190.

[22] Liu, H., Yan, F., Pan, Z., Lin, X., Luo, X., Shi, C., et al. (2015) Evaluation of Dual Energy Spectral CT in Differentiating Metastatic from Non-Metastatic Lymph Nodes in Rectal Cancer: Initial Experience. European Journal of Radiology, 84, 228-234.

[23] Bipat, S., Niekel, M.C., Comans, E.F.I., Nio, C.Y., Bemelman, W.A., Verhoef, C. and Stoker, J. (2012) Imaging Modalities for the Staging of Patients with Colorectal Cancer. The Netherlands Journal of Medicine, 70, 26-34.

[24] Artiko, V., Petrovic, M., Sobic-Saranovic, D., Antic, A., Koljevic-Markovic, A., Krajnovic-Jaksic, E., et al. (2011) Radioimmunoscintigraphy of Colorectal Carcinomas with 99m-Tc-Labelled Antibodies. Hepato-Gastroenterology, 58, 347-351.

[25] Kato, T., Uehara, K., Ishigaki, S., Nihashi, T., Arimoto, A., Nakamura, H., et al. (2015) Clinical Significance of Dual-Energy CT-Derived Iodine Quantification in the Diagnosis of Metastatic LN in Colorectal Cancer. EJSO, 41, 1464-1470.

[26] Whiting, P., Rutjes, A.W.S., Reitsma, J.B., Bossuyt, P.M.M. and Kleijnen, J. (2003) The Development of QUADAS: A Tool for the Quality Assessment of Studies of Diagnostic Accuracy Included in Systematic Reviews. BMC Medical Research Methodology, 3, 25. https://doi.org/10.1186/1471-2288-3-25

[27] NHMRC (1999) A Guide to the Development, Implementation and Evaluation of Clinical Practice Guidelines. Commonwealth of Australia, Canberra.

[28] Rau, C., Blanc, B., Ronot, M., Dokmak, S., Aussilhou, B., Faivre, S., et al. (2012) Neither Preoperative Computed Tomography nor Intra-Operative Examination can Predict Metastatic Lymph Node in the Hepatic Pedicle in Patients with Colorectal Liver Metastasis. Annals of Surgical Oncology, 19, 163-168. https://doi.org/10.1245/s10434-011-1994-7

[29] Grobmyer, S.R., Wang, L., Gonen, M., Fong, Y., Klimstra, D., D’Angelica, M., et al. (2006) Perihepatic Lymph Node Assessment in Patients Undergoing Partial Hepatectomy for Malignancy. Annals of Surgery, 244, 260-264. https://doi.org/10.1097/01.sla.0000217606.59625.9d

[30] Liang, T.Y., Anil, G. and Ang, B.W.L. (2012) Imaging Paradigms in Assessment of Rectal Carcinoma: Loco-Regional and Distant Staging. Cancer Imaging, 12, 290-303. https://doi.org/10.1102/1470-7330.2012.0034

[31] Engelen, S.M.E., Beets, G. and Beets-Tan, R.G.H. (2007) Role of Preoperative Local and Distant Staging in Rectal Cancer. Onkologie, 30, 141-145.

[32] Vogel, W.V., Wierang, B., Corstens, F.H.M., Ruers, T.J.M. and Oyen, W.J.G. (2005) Colorectal Cancer: The Role of PET/CT in Recurrence. Cancer Imaging, 5, S143-S148. https://doi.org/10.1102/1470-7330.2005.0034

[33] De Gaetano, A.M., Vecchioli, A., Minordi, L.M., Parrella, A., Gaudino, S., Masselli, 
G., et al. (2000) Role of Diagnostic Imaging in Abdominal Lymphadenopathy. Rays, 25, 463-484.

[34] Theoni, R.F. (1997) Colorectal Cancer: Radiologic Staging. Radiologic Clinics of North America, 35, 457-485.

[35] Kwok, H., Bissett, I. and Hill, G.L. (2000) Preoperative Staging of Rectal Cancer. International Journal of Colorectal Disease, 15, 9-20. https://doi.org/10.1007/s003840050002

[36] Bipat, S., Glas, A., Slors, F.J., Zwinderman, A.H., Bossuyt, P.M. and Stoker, J. (2004) Rectal Cancer: Local Staging and Assessment of Lymph Node Involvement with Endoluminal US, CT, and MR Imaging-A Meta-Analysis. Radiology, 232, 773-783. https://doi.org/10.1148/radiol.2323031368

[37] Dighe, S., Purkayastha, S., Swift, I., Tekkis, P.P., Darzi, A., A'Hern, R. and Brown, G. (2010) Diagnostic Precision of CT in Local Staging of Colon Cancers: A Meta-Analysis. Clinical Radiology, 65, 708-719.

[38] Wang, C., Zhou, Z., Wang, Z., Zheng, Y., Zhao, G., Yu, Y., et al. (2005) Patterns of Neoplastic Foci and Lymph Node Micrometastasis within the Mesorectum. Langenbeck's Archives of Surgery, 390, 312-318. https://doi.org/10.1007/s00423-005-0562-7

[39] Deleau, C., Buecher, B., Rousseau, C., Kraeber-Bodere, F., Flamant, M., des Varannes, S.B., et al. (2011) Clinical Impact of Fluorodeoxyglucose-Positron Emission Tomography Scan/Computed Tomography in Comparison with Computed Tomography on the Detection of Colorectal Cancer Recurrence. European Journal of Gastroenterology \& Hepatology, 23, 275-281. https://doi.org/10.1097/MEG.0b013e328343eaa0

[40] Tsunoda, Y., Ito, M., Fujii, H., Kuwano, H. and Saito, N. (2008) Preoperative Diagnosis of Lymph Node Metastases of Colorectal Cancer by FDG-PET/CT. Japanese Journal of Clinical Oncology, 38, 347-353. https://doi.org/10.1093/jjco/hyn032

[41] Huppertz, A., Franiel, T., Wagner, M., Puttcher, O., Wagner, J., Rief, M., et al. (2011) Whole-Body MRI with Assessment of Hepatic and Extraabdominal Enhancement after Administration of Gadoxetic Acid for Staging of Rectal Carcinoma. Acta Radiologica, 8, 842-850.

[42] Chan, K., Welch, S., Walker-Dilks, C. and Raifu, A. (2012) Evidence-Based Guideline Recommendations on the Use of Positron Emission Tomography Imaging in Colorectal Cancer. Clinical Oncology, 24, 232-249.

[43] Brown, G., Richards, C.J., Bourne, M.W., Newcombe, R.G., Radcliffe, A.G., Dallmore, N.S. and Williams, G.T. (2003) Morphologic Predictors of Lymph Node Status in Rectal Cancer with Use of High-Spatial Resolution MR Imaging with Histopathologic Comparison. Radiology, 227, 371-377.

https://doi.org/10.1148/radiol.2272011747

[44] Lahaye, M., Engelen, S. and Kessels, A. (2008) USPIO-Enhanced MR Imaging for Nodal Staging in Patients with Primary Rectal Cancer: Predictive Criteria. Radiology, 246, 804-811. https://doi.org/10.1148/radiol.2463070221

[45] Cho, E.Y., Kim, S.H., Yoon, J.H., Lee, Y., Lim, Y.J., Kim, S.J., et al. (2013) Apparent Diffusion Coefficient for Discriminating Metastatic from Non-Metastatic Lymph Nodes in Primary Rectal Cancer. European Journal of Radiology, 82, e662-e668.

[46] Sundlisaeter, E., Dicko, A., Sakariassen, P.O., Sondenaa, K., Enger, P.O. and Bjerkvig, R. (2007) Lymphangiogenesis in Colorectal Cancer-Prognostic and Therapeutic Aspects. International Journal of Cancer, 121, 1401-1409.

https://doi.org/10.1002/ijc.22996 
[47] Nagahashi, M., Ramachandran, S., Rashi, O.M. and Takabe, K. (2010) Lymphangiogenesis: A New Player in Cancer Progression. World Journal of Gastroenterology, 16, 4003-4012. https://doi.org/10.3748/wjg.v16.i32.4003

[48] Ercolani, G., Grazi, G.L., Ravaioli, M., Grigioni, W.F., Cescon, M., Gardini, A., et al. (2004) The Role of Lymphadenectomy for Liver Tumours: Further Considerations on the Appropriateness of Treatment Strategy. Annals of Surgery, 239, 202-209. https://doi.org/10.1097/01.sla.0000109154.00020.e0

[49] Leong, S.P.L., Nakakura, E.K., Pollock, R., Choti, M.A., Morton, D.L., Henner, W.D., et al. (2010) Unique Patterns of Metastases in Common and Rare Types of Malignancy. Journal of Surgical Oncology, 103, 607-614. https://doi.org/10.1002/jso.21841

[50] Moszkowicz, D.C.F., Dokmak, S. and Belghiti, J. (2012) Routine Pedicular Lymphadenectomy for Colorectal Liver Metastases. American College of Surgeons, 214, e39-e45.

Submit or recommend next manuscript to SCIRP and we will provide best service for you:

Accepting pre-submission inquiries through Email, Facebook, LinkedIn, Twitter, etc. A wide selection of journals (inclusive of 9 subjects, more than 200 journals)

Providing 24-hour high-quality service

User-friendly online submission system

Fair and swift peer-review system

Efficient typesetting and proofreading procedure

Display of the result of downloads and visits, as well as the number of cited articles

Maximum dissemination of your research work

Submit your manuscript at: http://papersubmission.scirp.org/

Or contact ojmi@scirp.org 